\title{
The Understandable English Conversational Implicatures by Yemeni EFL University Learners
}

\author{
Haifa Mohammad Ahmad Nassar \\ Assistant Lecturer of English, Hajjah University, Yemen \\ haifaaama@gmail.com
}

Abdusalam M. Gh. Al-Ghrafy
Associate Professor of Linguistics, Sana'a University, Yemen

DOI: https://doi.org/10.36892/ijlls.v2i1.151

$\begin{array}{ll}\text { Received: } & \text { Abstract } \\ 30 / 1 / 2020 & \text { English, as a communication tool, plays an extremely significant role in } \\ \text { cross-cultural communication. While it is true that language users can mean } \\ \text { Accepted: } \\ \text { exactly what they mean in their utterances, it is also true that they can have } \\ \text { their utterances mean much more than what they say. Speakers of English } \\ \text { choose to speak indirectly, and that using conversational implicatures is a } \\ \text { weyy to be indirect. This research paper examines the perception of English } \\ \text { Perception; English } & \text { conversational implicatures among Yemeni EFL university learners. It } \\ \text { Conversational } & \text { follows an empirical analytical-descriptive method consisting of a test and } \\ \text { Implicatures; Speech } & \text { an interview. The study subjects were } 62 \text { Yemeni EFL university learners. A } \\ \text { Learner } & \text { multiple-choice discourse completion test MCDCT ) and an interview were } \\ & \text { used for collecting the study data. The test contains six types of } \\ & \text { conversational implicature: Stating, Tautology, Rhetorical Question, } \\ & \text { Understatement, Indirect Refusal and Indirect Request. All the implicatures } \\ \text { included in the test were adapted from the study related literature including } \\ \text { Grice (1989), Hurford, Heasley, and Smith (2007), and Sharpe (2007), } \\ \text { whereas most of the test scenarios containing these implicatures were ready- } \\ \text { made ones that the researcher came across throughout her reading. The } \\ \text { results revealed that these implicatureswere found easy by Yemeni EFL } \\ \text { university learners to understand. Hence, Yemeni EFL university learners } \\ \text { should practice through diverse tasks that involve various conversational } \\ \text { implicatures especially the ones that have similarities in the way in which } \\ \text { interactions are carried out under certain circumstances in English and } \\ \text { Arabic. The process would ease the concern of EFL students about English } \\ \text { conversational implicature, build up their confidence and enhance language } \\ \text { learning. }\end{array}$

\section{INTRODUCTION}

Pragmatics is the study of language from the point of view of users, especially of the choices they make, the constraints they encounter in using language in social interaction, and the effects their use of language have on other participants in the act of communication (Crystal, 2008). Meaning, as one of the key concepts in pragmatics, is one of the most controversial points that cause many problems in communication (Allott, 2010). This is because tracing the sense of a particular linguistic item sometimes does not only call upon linguistic knowledge but on pragmatic knowledge as well (Kehal, 2010). 
Grice $(1975,1989)$ as the founder of the concept of 'implicature' deals with an explication of a speaker's meaning in terms of intentions. He differentiates between what an utterance conventionally means and what it pragmatically means. He suggests that conversation is a characteristically purposeful and cooperative enterprise governed by what he calls the Cooperative Principle (CP). This principle together with its four maxims will be expected to be observed and obeyed by interlocutors in a talk exchange. Consequently, the principle generally assumes that conversation partners will be cooperative: informative, truthful, relevant, and succinct. Hence, if things are communicated, even though they are not clearly expressed, then a conversational implicature works (Grice, 1975,1989).

A conversational implicature is a case in which a speaker produces a coded utterance to convey certain intention. The listener analyzes and interprets the communicative intention that has been revealed by the speaker. A speaker A, for example, says 'Will Sally be at the meeting?' and B says 'Her car broke down'. The meaning is 'Sally will not be at the meeting'. Although native speakers grasp it smoothly, it may become rather problematic for EFL learners because their lack of exposure to authentic English use outside the classroom and they only practise English in their classroom. More specifically, this research paper aims to find out what English conversational implicatures are easily perceived by Yemeni EFL university learners.

\section{STATEMENT OF THE PROBLEM}

Language is a cultural medium that allows its users to reflect different elements that define their identity, such as educational background, tradition, beliefs and even emotional states. Cultural characteristics and features are common in every language, however, languages can share some of these features that shape the ways languages are spoken. No pairs of languages overlap each other completely, but they may share some norms either in terms of pragmatic meaning of expression or their function in communication.

Pragmatically speaking, English like other languages, has got its own unique features and shared features with other languages. Grice (1975) and other theorists such as Brown and Levinson (1987), and Leech (1983), for example, have attempted to formulate universals in language use. That is, universal applicable rules may be shared in language use such as in English and Arabic. Conversational implicature, which is an essential element in language use (pragmatics), refers to the ability to recognize what is meant by what is said (Grice, 1975). Huang (2011) further considers it universal because it is motivated rather than arbitrary.

In many cases, implicatures are not present in the students' first languages, so they are considered to be new concepts, but in the cases where implicatures are present in the students' first languages, the exposure to these concepts raises students' awareness that such implicatures alsohappen in English. Therefore, different English conversational implicatures can be researched to know the extent to which they are understood by Yemeni EFL university learners. Thus, the purpose of the current study is to identify the types of English conversational implicatures that are easily interpreted by the learners.

\section{OBJECTIVES OF THE STUDY}

This study aims to:

1. examine the extent to which different English conversational implicatures are understood by Yemeni EFL university learners;

2. identify the types of English conversational implicatures that are easily interpreted by these learners; and 
3. shed light on the reason/s behind the learners' understanding of these implicatures.

\section{LITERATURE REVIEW}

Language is an important part of people's everyday life as it is their tool to communicate with each other. Language thereby is used to transmit ideas, feelings, and thoughts. Leech (1983) argues "We cannot really understand the nature of language itself unless we understand pragmatics" (p.34). Thus, pragmatics is regarded as a vital means by which meanings derived from specific kinds of speech situations.

\section{Theoretical Implications of Conversational Implicature}

The emergence of what is often called modern pragmatics today is mainly included under the two prominent theories: speech act theory and conversational implicature theory as referred by Mey (2009). They are discussed in the following section.

\section{Theory of Conversation}

Grice $(1975,1989)$ proposes that participants in a communicative exchange are guided by the $\mathrm{CP}$ that determines the way in which language is used with maximum efficiency and effect to achieve rational communication. The $\mathrm{CP}$ states that make your conversational contribution such as is required, at the stage at which it occurs, by the accepted purpose or direction of the talk exchange in which you are engaged. This principle is an umbrella term for nine components that guide how we communicate. These nine components are grouped together into the four conversational categories or maxims of quality (truthfulness), quantity (informativeness), relation (relevance), and manner (perspicuity).

The CP aims at guiding participants in using language efficiently and effectively, and towards achieving cooperative goals. In other words, it assumes that people taking part in communication expect themselves and the others to be cooperative, that is, be truthful, be informative, be relevant and be brief. Implicatures are generated when the audience realizes that an assumption is incompatible with the speaker intending to communicate what was said by the utterance. The audience is led to look for some other content the speaker might intend to get across. This other content is the implicature. Green (1989) claims that it is a fact of all languages, a strategy frequently used in communication. In one model of pragmatic ability, pragmatic awareness can be characterized as the comprehension of speech acts and conversational implicatures (Thomas, 2013). Therefore, speech acts are an important aspect of pragmatics.

The notion of speech acts as developed by John Austin (1962) captures an essential aspect of language use: the fact that an utterance, which expresses some propositional content, may at the same time count as the performance of a communicative act. So, speech acts are actions of doing something through speaking.

The performance of a speech act depends on the context within which the utterance occurs; thecontext consisting of all the relevant information relating to participants, and the temporal and spatial parameters of the speech event.

Speech acts can be also recognized with regard to their structure. Whenever there is a direct relationship between the function of a speech act and its structural form, we have a direct speech act. On the other hand, when there is no direct relationship between a structure and a form, but rather an indirect one, the speech act is considered indirect.

Austin (1962) argues that "To determine what illocutionary act is so performed we must determine in what way are using the locution" (p.98). This means that what is said (the 
locutionary act) does not determine the illocutionary act(s) being performed. Thus, we can perform a speech act directly or indirectly, by way of performing another speech act. Searle (1979) states that an indirect speech act is one "performed by means of another" (p.60). That means that there is an indirect relationship between the form and the function of the utterance. Morgan (1978) and Gibbs (1983) state that some indirect speech acts operate as implicatures. The speech act of requesting, for example, is very rarely performed by means of an imperative in English. Instead, it is standardly carried out indirectly. Both speech acts and conversational implicatures deal with indirectness in human communication.

\section{METHODOLOGY}

The study is both quantitative and qualitative since the students' wrong or right responses in understanding each implicature in the study test are counted in numbers, whereas the participants' responses to the study interview question is explained in words. For the sake of reliability, the research test was validated by seven experts in the field of pragmatics. Experts' judgments helped to include plausible and consistent scenarios.

Prior to conducting the study test, a pilot study was conducted on a group of $10 \%$ of the number of the study population to examine the techniques needed for administering the test. The other purpose of the pilot study was to investigate the possibilities of undertaking it in collecting the related data. The pilot study was conducted one week before administering the test from which the students who had participated in the pilot task were excluded.

The population of the study consisted of the fourth level students at theDepartmentof English, Faculty of Education- Sana'a University. 50\% of the study population was selected as the study sample. The purpose of deciding such percentage was to make the study sample representative for the whole population. This was based upon the principle that a larger sample size would ensure the inclusion of subjects with diverse pragmatic backgrounds. The study sample was selected by using simple random sampling technique. According to Brink (1996), Burns and Grove (2001), a random sampling ensures that all the participants have an equal chance to be selected and it avoids selection bias and thus typically reflects the characteristics of the population as a whole. The sample of the interview was only $10 \%$ and the interview was carried out after conducting the study test.

After administering the study test, an analysis of the subjects' responses was conducted to identify test items difficulty, using the Statistical Package for Social Sciences (SPSS) version 25. The difficulty of a test item is understood by the proportion of the subjects who answered the test item correctly. If this proportion is equal or higher than $50 \%$, the implicature is considered to be easy for them. However, if it is less than $50 \%$, the implicature is considered to be difficult for them. To calculate the difficulty of an item, the number of subjects who answered it correctly is divided by the total number of the subjects who answered it (correctly and incorrectly) multiplied by 100 . Usually this proportion is indicated by the letter $\rho$, which denotes the difficulty of the item (Crocker and Algina, 1986). It is calculated by the following formula:

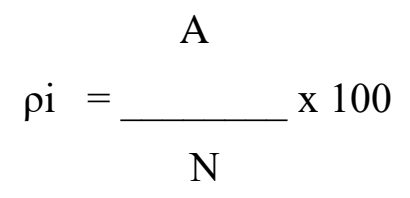


Where:

$\rho i=$ Difficulty index of item $\mathrm{i}$

$A=$ Number of correct answers to item $\mathrm{i}$

$\mathrm{N}=$ Number of correct answers plus number of incorrect answers to item $\mathrm{i}$

In the research test, each implicature type is presented by two scenarios to ensure that the subjects understand the six implicature types thoroughly. If both proportions of the same type of implicature are equal to $50 \%$ or higher than it, it will be clear that this type of implicature is easy for the subjects. Similarly, if these proportions are less than $50 \%$, this will denote that this kind of implicature is difficult for them. However, in case the proportions of the subjects in responding to the two test scenarios that involve the same type of implicature are different. The proportion of one of them, for example, indicates that it is easy for the subjects whereas the proportion of its counterpart denotes that it is difficult for them. Here the frequency of the subjects' right choice acrossthe two same type implicature test scenarios was compared with the frequency of the incorrect choice of the pair of them. In other words, making decision of the implicaturetype's ease or difficulty was based on the frequency of the right choice in both same type implicature test scenarios by every subject. If the frequency of the right answer selected by every subject in both same type implicature scenarios was higher than the frequency of the incorrect answer of the pair of them, the implicature type is considered to be easy for the subjects; otherwise it would be difficult for them.

After the test was administered, the structured interviews were conducted to have a clear vision of the subjects' performance.

\section{FINDINGS}

The findings of this study showed that all the study test implicatures were interpreted correctly by the subjects. The English conversational implicatures were understood by Yemeni EFL university learners to a large extent.This section presents a summary of the easy English conversational implicatures according to the study test. It also presents discussion of the responses to interview question and the interpretation of the study results. The test results show that stating, tautology, rhetorical question and understatement implicatures are easy for Yemeni EFL university learners to interpret. Both levels of difficulty of the pair of stating, tautology, rhetorical question and understatement implicatures are either equal or higher than $50 \%$. The following tables and figures show these results:

Stating:It is a generalized implicature which is obtained from the speaker's utterance when the speaker observes the cooperative principle and its maxims. This inference is generated by flouting of a maxim, failure to perform a maxim, particularly the first maxim of quantity (Grice, 1989, p. 38).Table 1 lists the levels of difficulty and frequencies of test scenarios 1 and 2: 
Table 1. Test Scenarios $1 \& 2$

\begin{tabular}{|c|c|c|c|c|c|}
\hline \multicolumn{3}{|c|}{ Scenario 1} & \multicolumn{3}{|c|}{ Scenario 2} \\
\hline Generalized & \multirow{2}{*}{$\begin{array}{l}\text { Level of } \\
\text { Difficulty }\end{array}$} & \multirow{2}{*}{ Frequency } & Generalized & Level of & Frequency \\
\hline Stating & & & Stating & Difficulty & гrequency \\
\hline Incorrect Responses & $23 \%$ & 14 & Incorrect Responses & $47 \%$ & 29 \\
\hline Correct Responses & $77 \%$ & 48 & Correct Responses & $53 \%$ & 33 \\
\hline Total & $100 \%$ & 62 & Total & $100 \%$ & 62 \\
\hline
\end{tabular}

As shown in Table 1, stating is the easiest implicature for the subjects. The levels of difficulty of the two test scenarios are $77 \%$ and $53 \%$, respectively. Here is a transcript of first research test scenario: A woman and a man are talking about travelling.

Woman: If I were you, I would take a plane instead of bus. It will take you forever to get there.

Man: But flying makes me so nervous.

QUESTION: Which of the following says what the man meant?

a) He prefers taking a bus because it makes him feel more relaxed.

b) He prefers taking a plane because the bus is too slow.

c) He prefers staying at home because he does not like to travel.

d) He does not prefer to travel with the woman.

The subjects reported that this situation was familiar to them. It had an equivalent in the Yemeni Arabic and it is linguistically inferred from the speakers' utterances. One of them said, "This situation is clear. The plane makes him nervous, so the bus makes him relaxed." Consequently, as this is a generalized implicature that involves using expectations of the context in order to calculate a speaker's attitude or intention from the overall interaction, many subjects successfully got its meaning. The subjects seemed to attend more closely to linguistic cues to interpret meaning. Figure 1 shows the frequencies of the subjects, (0.00) who incorrectly responded to both stating implicatures, (1.00) who once correctly responded to one of them and failed the other, and (2.00) who correctly chose the right answers in both implicature scenarios.

Figure 1.Pinpoints the Frequencies of both Stating Implicatures
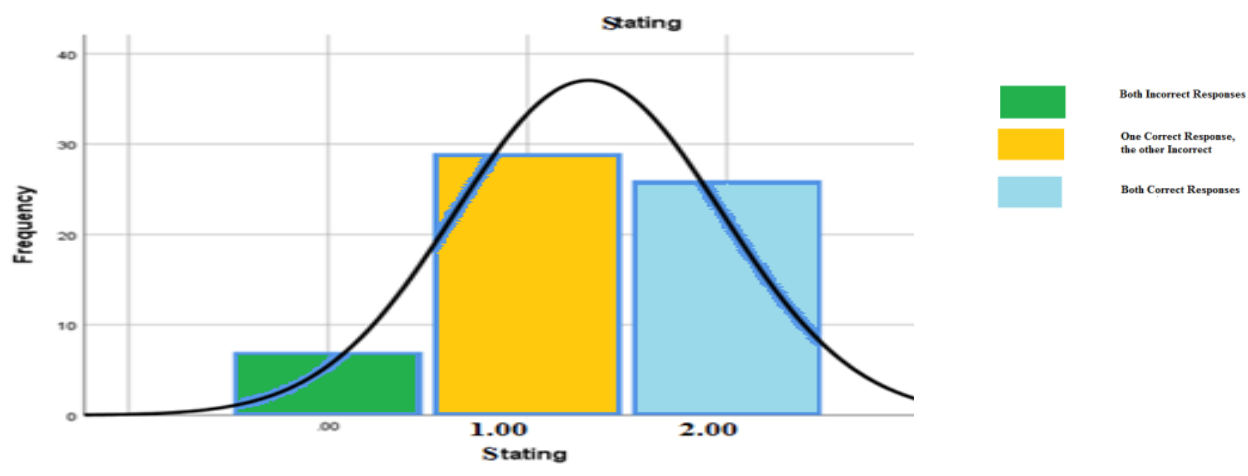
As shown in Figure 1, the frequency of the correct answer of the two stating implicatures in the two situations (more than 20 students) is higher than the incorrect answers (less than 10 students). The majority of the subjects selected the appropriate answer. Approximately, more than one third of the subjects comprehended both stating implicatures.

Tautology: According to Grice's maxim of quantity, cooperative speakers do not produce uninformative utterance. As it turns out, utterances, like "a sandwich is a sandwich" and "war is war", are very informative. Table 2 presents the test results of the two tautology scenarios.

\section{Table 2. Test Scenarios $3 \& 4$}

\begin{tabular}{|c|c|c|c|c|c|}
\hline \multicolumn{3}{|c|}{ Scenario 3} & \multicolumn{3}{|c|}{ Scenario 4} \\
\hline Particularized & \multirow{2}{*}{ Level of Difficulty } & \multirow{2}{*}{ Frequency } & Particularized & \multirow{2}{*}{ Level of Difficulty } & \multirow{2}{*}{ Frequency } \\
\hline Tautology & & & Tautology & & \\
\hline Incorrect Responses & $24 \%$ & 15 & Incorrect Responses & $48 \%$ & 30 \\
\hline Correct Responses & $76 \%$ & 47 & Correct Responses & $52 \%$ & 32 \\
\hline Total & $100 \%$ & 62 & Total & $100 \%$ & 62 \\
\hline
\end{tabular}

The table 2 shows that the tautology implicatures were also easy for the subjects as most of them selected the correct choice. The levels of difficulty of these implicatures are $76 \%$ and $52 \%$ in a row. This indicates low levels of difficulty. The following is the transcript of the test scenario 3:

In the cafeteria of a university, Joan asks her friend, Margaret, about the sandwich she is going to have.

Joan: How do you like your sandwich to be?

Margaret: A sandwich is a sandwich.

QUESTION: Which of the following says what Margaret meant?

a) I don't like sandwiches.

b) No matter what kind of sandwich I'll have.

c) I don't know. Ask me a question I can answer.

d) Almost everyone else will eat sandwiches.

When the interviewees were asked about this test scenario, the majority commented that they got the meaning of this implicature easily. Margaret tried to say that "I am hungry and no matter what kind of sandwich I'll have". It is the same to what Yemeni people usually say "Alhasel" which means (I'll be satisfied with whatever you bring to me). 


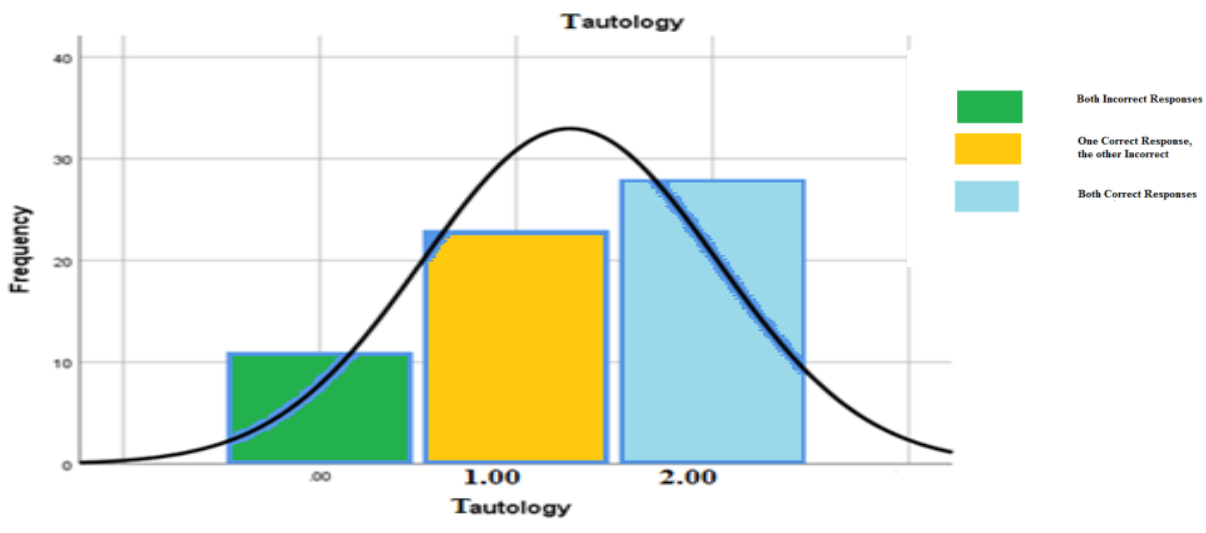

It is apparent from Figure 2 above that the correct answers of the two tautology implicatures are more than theincorrect ones. The number of the subjects who selected the correct alternatives in both scenarios is 30 students whereas the number of those who chose the incorrect ones is only 12. The easiness of this type of implicature for the study subjects to interpret could be attributed to the existence of similar mplicatures in their first language.

Rhetorical Question:This scenario includes a particularized implicature because the speaker flouted the maxim of quality of the cooperative principle and forces the listener to infer the meaning according to the specific context. Levinson (1983) argues that some conversational implicatures are generated by flouting the maxim of quality in forms of rhetorical question.

\section{Table 3.Test Scenarios 5 \& 6}

\begin{tabular}{|c|c|c|c|c|c|}
\hline \multicolumn{3}{|c|}{ Scenario 5} & \multicolumn{3}{|c|}{ Scenario 6} \\
\hline Particularized & \multirow[b]{2}{*}{ Level of Difficulty } & \multirow[b]{2}{*}{ Frequency } & Particularized & \multirow{2}{*}{$\begin{array}{r}\text { Level of } \\
\text { Difficulty }\end{array}$} & \multirow[b]{2}{*}{ Frequency } \\
\hline Rhetorical Question & & & $\begin{array}{l}\text { Rhetorical } \\
\text { Question }\end{array}$ & & \\
\hline Incorrect Responses & $26 \%$ & 16 & Incorrect Responses & $45 \%$ & 28 \\
\hline Correct Responses & $74 \%$ & 46 & Correct Responses & $55 \%$ & 34 \\
\hline Total & $100 \%$ & 62 & Total & $100 \%$ & 62 \\
\hline
\end{tabular}

As shown in Table 3, the rhetorical question implicatures are also easy for the Yemeni EFL university learners. The levels of difficulty of the pair of them are $74 \%$ and $55 \%$, consecutively. Here is a transcript of the test scenario 5:

Two roommates, Larry and Linda, are talking about what they are going to do during the summer.

Larry: My mother wants me to stay home and entertain the relatives when they come to visit us at the beach.

Linda: Do you have a lot of relatives?

Larry: Is the sky blue? 
QUESTION: Which of the following says what Larry meant?

a) Larry thinks her relatives are all blue.

b) Larry doesn't have many relatives.

c) Larry does have a lot of relatives.

d) Larry is new to the area and trying to find out what the summers are like.

In this test scenario, the vast majority of subjects (46) chose the expected answer, choice c. It is obvious that Larry had a lot of relatives. If she had not, she would say "no" or any similar answer. Instead, she asked a question. Asking such aquestion indicated that Larry actually did have a lot of relatives.

Not surprisingly, the rhetorical question implicatures were easy for the subjects to understand because they were presented in their first language. The interviewees gave some fine examples of the Yemeni Arabic rhetorical questions, such as "و هل يخفى القمر ") (Can the moon be hidden?) and "وهل هذا سؤال؟" (Is this a question?), and many others, which are used to say "Yes" or to show one's emphatic agreement to what one is asked about.

Figure 3.Below Pinpoints the Test Rhetorical Question Implicature Scenarios:

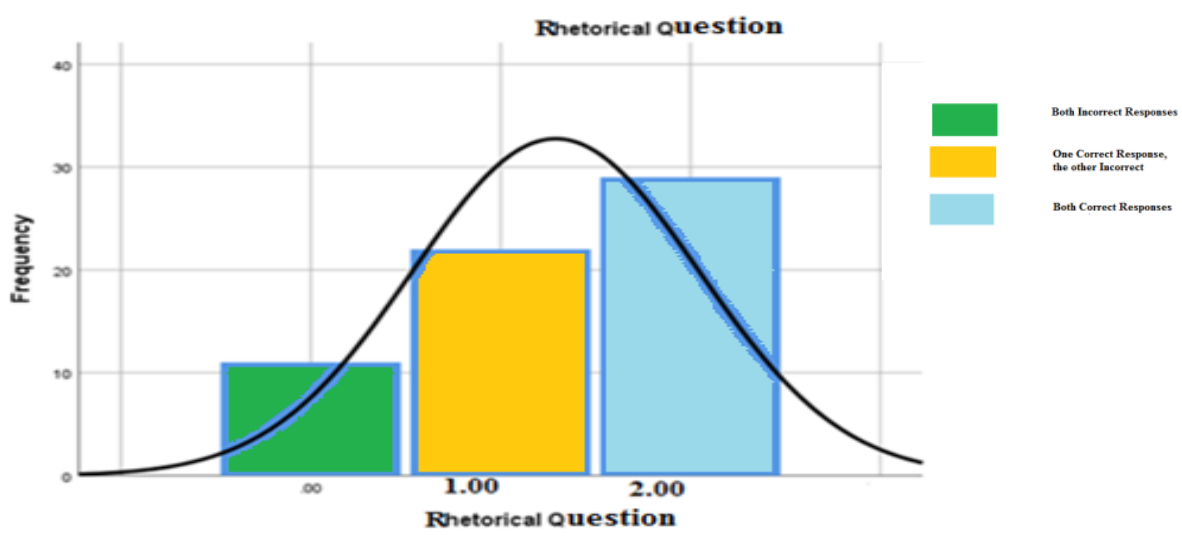

The frequency of the correct choices in the test rhetorical question implicatures of the scenarios 5 and 6 is higher than the incorrect choices as presented in Figure 3. The number of students who chose the expected answers of the two scenarios gets close to 30. On the other hand, the number of the subjects who selected the incorrect alternatives in both of them is just 12 . Therefore, this shows that this type of implicature is easy for Yemeni EFL university learners. This finding is consistent with the study result of Broersma (1994),who states that the rhetorical question implicatures "were easier to teach and easier for students to grasp" (p. 10).

Understatement: Most of the study subjects succeeded to comprehend the understatement implicatures. Both test scenarios 7 and 8 of the understatement implicatures were understood by the subjects. Table 4 presents the test results. 
Table 4.Test Scenarios $7 \& 8$

\begin{tabular}{|c|c|c|c|c|c|}
\hline \multicolumn{3}{|c|}{ Scenario 7} & \multicolumn{3}{|c|}{ Scenario 8} \\
\hline Particularized & \multirow{2}{*}{ Level of Difficulty } & \multirow{2}{*}{ Frequency } & Particularized & \multirow{2}{*}{ Level of Difficulty } & \multirow{2}{*}{ Frequency } \\
\hline Understatement & & & Understatement & & \\
\hline Incorrect Responses & $45 \%$ & 28 & Incorrect Responses & $47 \%$ & 29 \\
\hline Correct Responses & $55 \%$ & 34 & Correct Responses & $53 \%$ & 33 \\
\hline Total & $100 \%$ & 62 & Total & $100 \%$ & 62 \\
\hline
\end{tabular}

Table 4shows the levels of difficulty and the frequencies of correct and incorrect answers in the pair of the understatement implicature scenarios. Once again, the result indicates that this kind of conversational implicatures is an easy task for the subjects. The extract below shows the test scenario7:A woman and her husband are talking about the last night movie.

Woman: That was a great movie!

Husband: Sure, if you like fairy tales.

QUESTION: Which of the following says what the man meant?

a) He liked the movie because it was a fairy tale.

b) He was impressed with the movie.

c) He agreed with the woman about the movie.

d) He didn't agree with the woman about the movie.

The results indicate that over half of the subjects understood and detected a note of sarcasm (irony) in the husband's utterance "Sure, if you like fairy tales", and they correctly chose alternative d. Although there is a lack of straightforwardness in the husband's response, the message was decoded by many subjects. In the interview, they indicated that there were some similar utterances like the one in the above context used in Yemeni Arabic and they usually use them in their daily exchange to make ridicule of their peers, including"دكم عند أصنج" (drum near a deaf person) and "الطول طول و العقل عقل عصفور" (an attractive man with little mind). The former is used as an implicature for expressing annoyance when an addressee disappoints a speaker's expectations and what the speaker has done for a hearer or informed him all went away. However, the latter is used deridingly to implicate that despite all good intentions, an addressee or hearer seems to have too low-level for expectations. Moreover, understatement (irony) is also a rich phenomenon in the Holy Qur'an, the sacred book of the majority of Arabic speakers. 
Figure 4.Below Presents the Frequencies of the Correct and Incorrect Answers of the Test Understatement Implicatures

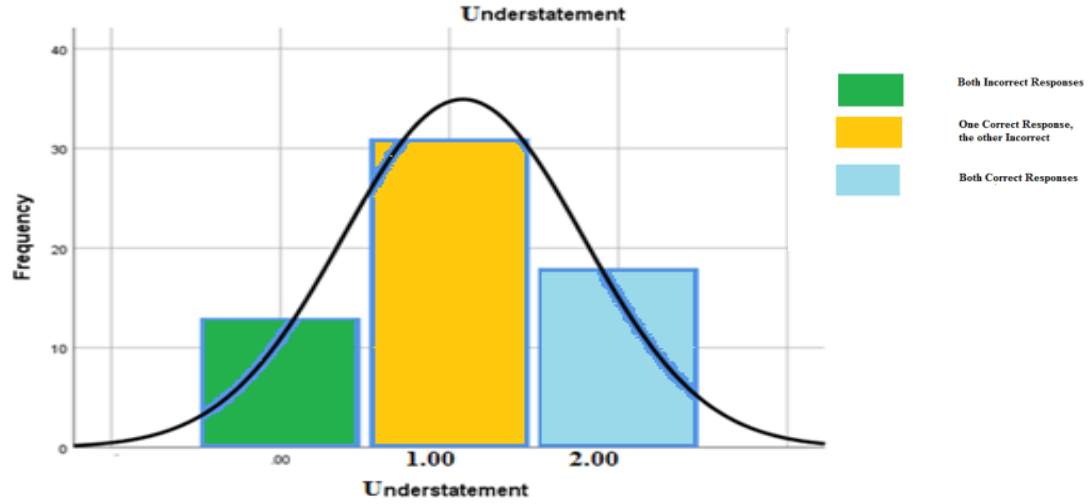

As shown above, the frequencies of the correct answers to both scenarios of the understatement implicatures appear to be more than the incorrect ones. The number of subjects who chose the expected answer in both scenarios is 18, however about 12 subjects selected the incorrect answers.

Indirect Refusal: It is a particularized implicature in which the quantity maxim is flouted. The maxim regulates that hearers are to make their contributions as informative as it is required for the current purposes of the exchange. Table 5 below presents the test results of the two scenarios of indirect refusal implicatures.

Table 5.Test Scenarios $9 \& 10$

\begin{tabular}{|c|c|c|c|c|c|}
\hline \multicolumn{3}{|c|}{ Scenario 9} & \multicolumn{3}{|c|}{ Scenario 10} \\
\hline Particularized & \multirow{2}{*}{ Level of Difficulty } & \multirow{2}{*}{ Frequency } & Particularized & \multirow{2}{*}{ Level of Difficulty } & \multirow{2}{*}{ Frequency } \\
\hline Indirect Refusal & & & Indirect Refusal & & \\
\hline Incorrect Responses & $26 \%$ & 16 & Incorrect Responses & $69 \%$ & 43 \\
\hline Correct Responses & $74 \%$ & 46 & Correct Responses & $31 \%$ & 19 \\
\hline Total & $100 \%$ & 62 & Total & $100 \%$ & 62 \\
\hline
\end{tabular}

As shown in the table above, the levels of difficulty of the two indirect refusal implicatures in the two scenarios are different. The implicature in scenario 9 is considered to be easy for the subjects to understand because its level of difficulty is 74\%. On the other hand, scenario 10 implicature is difficult for them as its level of difficultyis $31 \%$. The frequency of the correct alternatives to both scenarios of the indirect refusal implicatures compared to the frequency of the incorrect alternatives chosen by every subject was determined to identify whether this type of conversational implicatures was easy or difficult to them. 
Figure 5. Below Shows the Frequencies of the Correct and Incorrect Answers to the Two Indirect Refusal Implicatures

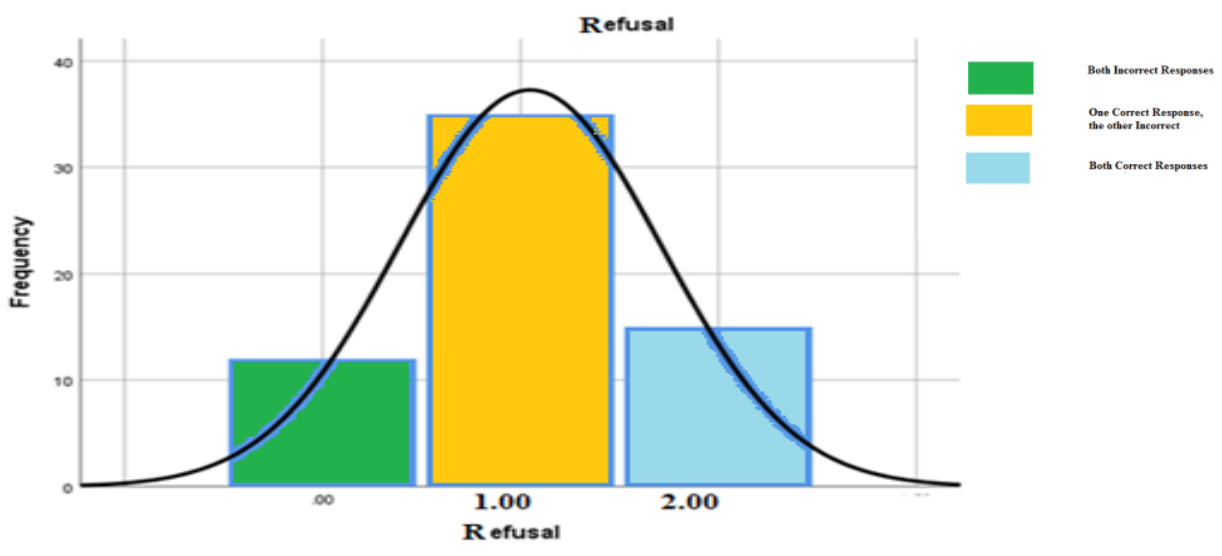

As is seen in the figure 5, the number of subjects who selected the appropriate answers in the pair of indirect refusal implicature scenarios is approximately 15, but the ones who chose the incorrect answers are almost 12. Thus, this type of conversational implicature is viewed to be easy for Yemeni EFL college learners. Test scenario 9 of an indirect refusal conversational implicature is shown in the following:

Susan is talking to Dave about the party that she is going to have on Saturday.

Susan: I'm having a party this Saturday, and it should be fun. I hope you can come.

Dave: Oh, Susan, I already have plans on Saturday.

QUESTION: Which of the following says what Dave meant?

a) Dave doesn't think Susan's party is exciting.

b) Dave can't come to Susan's party.

c) Dave likes his plans for Saturday.

d) Dave is going to attend Susan's party.

In response to the question: why do you think it was easy to select the correct alternative in situation (9)?, the majority of those interviewed indicated that they got the meaning of the scenario easily because they were familiar with such situations in their daily lives. They pointed out that the meaning was inferred from the clause:" I already have plans on Saturday". Dave gave Susan an excuse for not coming to her party. He meant that he wants to come but his timetable was full. He had plans on that day that would prevent him from coming to the party. Dave politely told Susan that he would not come.

This implicature is further considered as formulaic which has particular semantic and pragmatic patterns (e.g.; making excuse for somebody) and this may make it easier to understand. The study by Bouton $(1992,1994)$ expanded the taxonomy of implicatures by categorizing conversational implicaures as formulaic and idiosyncratic ones. Formulaic implicatures are these, which have particular semantic and pragmatic patterns, and idiosyncratic implicatures are these, which heavily depend on the context inherent in the conversation. 
Indirect Request: It is a particularized implicature in which the quantity maxim is flouted as the utterance is not informative as required. Table 6 below shows the test results of the levels of difficulty of the indirect request implicatures encompassed in the test scenarios 11 and 12:

\section{Table 6.Test Scenarios 11\&12}

\begin{tabular}{|c|c|c|c|c|c|}
\hline \multicolumn{3}{|c|}{ Scenario 11} & \multicolumn{3}{|c|}{ Scenario 12} \\
\hline Particularized & \multirow{2}{*}{ Level of Difficulty } & \multirow{2}{*}{ Frequency } & Particularized & \multirow{2}{*}{ Level of Difficulty } & \multirow{2}{*}{ Frequency } \\
\hline Indirect Request & & & Indirect Request & & \\
\hline Incorrect Responses & $40 \%$ & 25 & Incorrect Responses & $56 \%$ & 35 \\
\hline Correct Responses & $60 \%$ & 37 & Correct Responses & $44 \%$ & 27 \\
\hline Total & $100 \%$ & 62 & Total & $100 \%$ & 62 \\
\hline
\end{tabular}

As presented in the table 6 ,we notice that these levels indicate that the implicature in scenario 11 was easy for the subjects, however the implicature in scenario 12 was difficult for them to comprehend. Consequently, the frequency of the correct answers to both scenarios of the indirect refusal implicatures compared with the frequency of the incorrect answers chosen by every subject was determined toidentify whether this type of conversational implicatures was easy or difficult for them.

Figure 6.Below Pinpoints the Frequencies of Correct and Incorrect Answers of the Two Test Indirect Request Implicatures

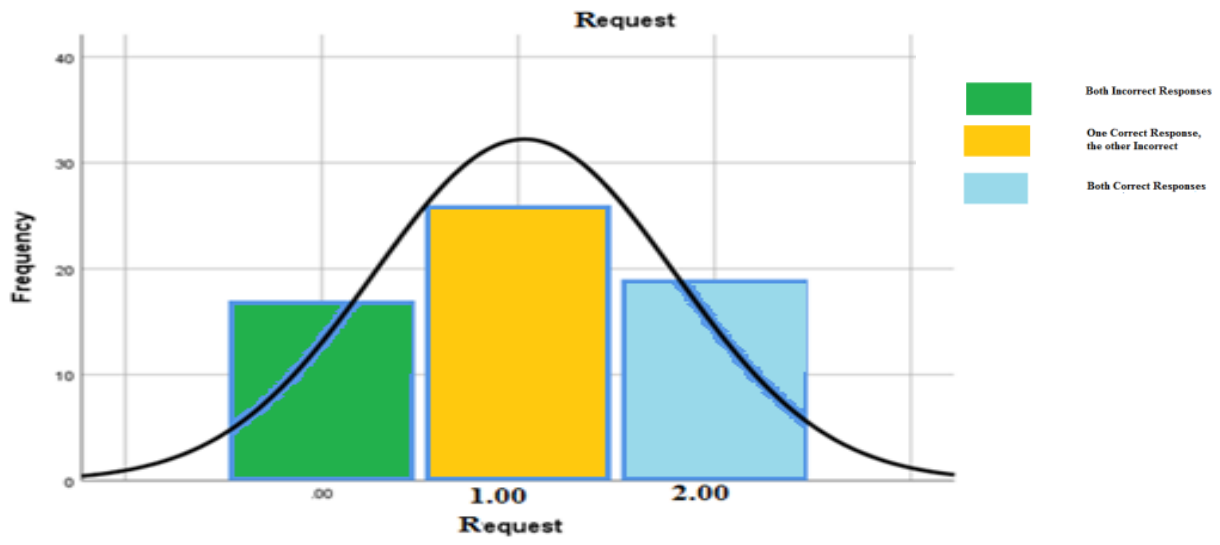

Results in the figure 6 show that the indirect request implicatures are easy for Yemeni EFL university learners, since the number of the subjects who selected the correct alternatives in both scenarios is about 20 students, whereas the number of those who chose the incorrect ones is only 17. The following is the script of test scenario 11:You provide your classmate who is a native speaker of English with an e-mail, but he cannot understand it.

Classmate: I can't understand this e-mail.

QUESTION: Which of the following says what the classmate meant?

a) He is provided with a wrong e-mail. 
b) He supposes that you have much knowledge about e-mails.

c) He requests some help from you.

d) He really hasn't read it well enough to know.

From the point of view of most of the interviewees, the implicature in the above scenario was easy to identify. They indicated that there are some Yemeni Arabic utterances equivalent to the one above. They added that they usually use these utterances in their daily conversations. For instance, when one of them needs some help from her classmate, she probably says " هذا الدرس "صعب (this lesson is difficult), which may denote that the speaker expects help from the addressee. Göyet al. (2012), who give an overview of different request production in three different populations: two groups of Turkish learners of English with differing proficiency levels and a group of American English speakers, finds that subjects performed similarly in the request situations. The difference in power between speakers was minimal.

\section{DISCUSSION}

The study results highlighted that equivalence of the test implicatures in Yemeni Arabic language, familiarity and formulaic pattern of others and the subjects' previous experience of such contexts made it an easy task for the study subjects to interpret these English conversational implicatures. Furthermore, some of the study implicatures exist in the Holy Qur'an which is the religious text of the subjects. That is, the level of awareness of target language pragmatic features increases as these implicatures are presented in the subjects' first language, familiar to them, experienced by them, or formulaic.

The findings are in line with the findings obtained in the studies by Broersma (1994), Bouton (1992, 1994), and Göy et al. (2012) who affirm the easiness of rhetorical question implicatures, formulaic implicatures and request production to be understood or produced by EFL and ESL students.

Since Yemeni EFL university learners have less opportunity to genuine language use, which helps them raising their pragmatic competence in general and the one regarding conversational implicature in specific, they need to be exposed to the most typical realization strategies of English conversational implicatures. If the these implicatures have equivalents in their first language, familiar to them, or formulaic, this will assist much to get over structural, social and cultural obstacles during interpreting them.

Considering the study results, most of the study subjects seem to be attentive to the similar and familiar pragmatic norms between their first language, Yemeni Arabic and English. Therefore, all the test conversational implicatures posed no obstacles for the subjects to understand. Thus, explicit instruction in pragmatic aspects of language, including implicature is a necessary component of EFL classroom instruction and curricula. This will better, develop and sharpen Yemeni EFL university learners' pragmatic competence.

\section{CONCLUSION}

The current research paper has demonstrated that various English conversational implicatures were grasped by Yemeni EFL college learners to a great extent. The most remarkable result to emerge from the data is that no particular problems were found with respect to understanding these implicatures as they were all familiar to them. They are stating, tautology, rhetorical question, understatement, indirect refusal, and indirect request. The data has been gathered 
from a sample of 62 Yemeni students at the Faculty of Education and it was assembled by the MCDCT and structured interviews.

In the analysis of the test scenarios, the researcher used the analytical-descriptive method: the test implicatures' difficulty levels, the frequency of the right choice across the two test implicatures of the same type, the knowledge presented by the interviewees, the analysis of socio-cultural similarities between Yemeni Arabic and English, and the Yemeni background knowledge. The study results revealed that all the six test conversational implicatures were never a problem for the subjects to comprehend. As these implicatures were familiar to the subjects, experienced by them, or existent in their first language, they are easy for them to interpret.

From the researcher point of view, language educators over the world have the responsibility to contribute towards inter-socio-cultural understanding and to help their students in the development of their pragmatic competences. Pragmatics becomes a useful discipline that allows language learners to learn a language appropriately throughout considering their first language pragmatic norms and their counterparts in English. As it turns out, the similarity between both languages, English and Yemeni Arabic, can be taken into account when developing Yemeni EFL college curricula. This will assist students in overcoming several problems including structural and socio-cultural difficulties. Finally, it is suggested that further research is needed to examine other different areas of pragmatics such as, presupposition and conversational analysis.

\section{REFERENCES}

Allott, N. (2010). Key Terms in Pragmatics. New York: Continuum International Publishing Group.

Austin, J. (1962). How to Do Things with Words. London: Oxford University Press.

Bouton, L. F. (1992). The interpretation of implicature in English by NNS: Does it come automatically without being explicitly taught?.Pragmatics and Language Learning, 3, 5365 .

Bouton, L. (1994). Can NNS skill in interpreting implicature in American English be improved through explicit instruction? --a pilot study. Pragmatics and Language Learning, 5, 89-109.

Brown, P. and Levinson, S. (1987). Politeness: Some Universals in Language Usage.Cambridge: Cambridge University Press.

Crystal, D. (2008). A dictionary of linguistics and phonetics. (6th Edition). Oxford: Blackwell Publishing.

Green, G. (1989) .Pragmatics and Natural Language Understanding. Hillsdale. NJ: Lawrence Erlbaum.

Gibbs, R. (1983). Do people always process the literal meanings of indirect requests? Journal of Experimental Psychology: Learning, Memory, and Cognition, 9, 524-533.

Grice, H. P. (1975). Logic and Conversation. In P. Cole and J. Morgan (Eds.), Syntax and Semantics, vol. 3 (pp.41-58).New York: Academic Press.

Grice, H.P. (1989). Studies in the Way of Words. Harvard University Press. 
Göy, E., Zeyrek, D., \&Otcu, B. (2012). Developmental patterns in internal modification of requests. In M. Economidou-Kogetsidis (Ed.), Interlanguage request modification (pp. 5186). Amsterdam, Netherlands: John Benjamins.

Huang, Y. ( 2011). Types of inference :entailment, presupposition, and implicature. In W. Bublitz\&N. Norrick (Eds.), Foundations of Pragmatics.(Vol. 1, pp. 397421).Berlin/Boston.Walter de Gruyter GmbH \&co.

Hurford, J., Heasley, B. \& Smith, M. (2007). Semantics: A Coursebook. New York. Cambridge University Press.

Kehal, M. (2010). Problems in English Arabic Translation of Reference Pragmatic Aspects. Unpublished M.A. thesis. Faculty of Letters and Languages, Mentori University. Algeria.

Leech, G. (1983). Principles of pragmatics. London: Longman.

Mey, J. (2009). Concise Encyclopedia of Pragmatics. Oxford: Elsevier.

Morgan, J. (978). Two types of convention in indirect speech acts. In P. Cole (ed.), Syntax and semantics Vol. 9: Pragmatics.(pp. 261-280). New York: Academic Press.

Searle, J. (1979). Expression and Meaning: Studies in the Theory of Speech Acts. Cambridge: Cambridge University Press.

Sharpe, P. (2007). Practice Exercises for the TOEFL: Test of English as a Foreign Language. 6th Edition. New York. Barron's Educational Series, Inc.

Thomas, J. (2013). Meaning in interaction: An introduction to pragmatics. Routledge.

\section{AUTHORS' BIO:}

Haifa Mohammad Ahmad Nassar is an assistant lecturer of English at Faculty of Education, Hajjah University, Yemen. She holds MA in TEFL, Sana'a University, 2013. She is currently a PhD candidate at the Department of English, Faculty of Languages, Sana'a University, Yemen. Her research interests include TEFL, Pragmatics, and Translation.

Abdusalam Mohammad Al-Ghrafy is an Associate Professor of Linguistics in English at Faculty of Languages, Sana'a University, Yemen. His research interests include Linguistics (pure\& applied), Semitic Linguistics, Historical Linguistics and Translation. 